Int. J. Electrochem. Sci., 13 (2018) $10514-10526$

\title{
Electrochemical Synthesis of the Composites Based on Multi- Wall Carbon Nanotubes and Polypyrrole Doped with Phosphomolybdic Acid Heteropolyanions and Their Vibrational Properties
}

\author{
M. Baibarac ${ }^{1, *}$, C. Serbschi ${ }^{2}$, M. Stroe ${ }^{l}$ \\ ${ }^{1}$ National Institute of Materials Physics, Lab. Optical Processes in Nanostructured Materials, P.O. Box \\ MG-7, Bucharest, R077125, Romania \\ ${ }^{2}$ Bioelectronic SRL, Cercelus street, no.54, Ploiesti, Romania \\ *E-mail: barac@infim.ro
}

doi: $10.20964 / 2018.11 .07$

Received: 17 June 2018 / Accepted: 20 August 2018 / Published: 1 October 2018

\begin{abstract}
Using cyclic voltammetry, Raman scattering and infrared (IR) spectroscopy, new findings concerning the electrochemical synthesis of composites based on multi-wall carbon nanotubes (MWNTs) and polypyrrole (PPY) doped with $\mathrm{H}_{3} \mathrm{PMo}_{12} \mathrm{O}_{40}$ heteropolyanions are described in this report. To better understand the electrochemical mechanism behind the synthesis of these composites, the influence of the concentrations of pyrrole and the electrolytes of $\mathrm{H}_{3} \mathrm{PMo}_{12} \mathrm{O}_{40}$ and $\mathrm{H}_{2} \mathrm{SO}_{4}$ on the cyclic voltammogram profile is studied. The formation of PPY doped with $\mathrm{H}_{3} \mathrm{PMo}_{12} \mathrm{O}_{40}$ heteropolyanions onto the MWNT surface is demonstrated by complementary studies of Raman scattering and IR spectroscopy.
\end{abstract}

Keywords: carbon nanotubes, polypyrrole, cyclic voltammetry

\section{FULL TEXT}

(C) 2018 The Authors. Published by ESG (www.electrochemsci.org). This article is an open access article distributed under the terms and conditions of the Creative Commons Attribution license (http://creativecommons.org/licenses/by/4.0/). 